\title{
RECIPROCIDADE, MORALIDADES E O ETHOS GUERREIRO NO URI: PRÁTICAS KAINGANG NA UNIVERSIDADE ESTADUAL DE LONDRINA
}

\author{
Ana Caroline Goulart ${ }^{1}$
}

\begin{abstract}
RESUMO
A partir de 2002, as universidades estaduais no Paraná foram marcadas pela presença de alunos kaingang e guarani, através do ingresso pelo Vestibular Diferenciado Indígena, sancionado pela Lei 11.345/01, no governo de Jaime Lerner, propiciando experiências diversas para esses grupos étnicos, tanto em seu sentido individual, quanto coletivo. Muitos projetos e expectativas são construídos para a formação superior indígena, envolvendo diferentes agentes e situações. Enfatizo neste artigo os sentidos das relações entre alunos e lideranças kaingang e os agentes institucionais nesse novo contexto, olhando para essas relações como sendo pautadas pela reciprocidade que, por sua vez é produtora dos conflitos, conflitos que são interpretados como geradores de trocas e potencializadores de uma identidade produzida e reorganizada na universidade.
\end{abstract}

Palavras-chave: Ensino superior. Kaingang. Agência. Paraná.

\footnotetext{
${ }^{1}$ Mestre pela Universidade Federal do Paraná. E-mail para contato: carolgoulart2@gmail.com
} 


\title{
RECIPROCITY, MORALITY AND THE WARRIORS ETHOS \\ IN THE URI: KAINGANG PRACTICE AT \\ UNIVERSIDADE ESTADUAL DE LONDRINA
}

\begin{abstract}
Since 2002 Paraná State Universities have been marked by kaingang and guarani students presence, admission through "Vestibular Diferenciado Indígena", passed by law 11.345/01, during Jaime Lerner's administration, that could provide a variety of experiences, in individual and collective point of views, to those ethic groups. There are many projects and prospects for indigenous high education which involve different agents and situations. The meaning of the relationships among students, kaingang leadership and the institutional agency are stressed in this article, and such relationships are seen as ruled by reciprocity, which in turn generates conflicts. These conflicts are interpreted as a generator of exchanges and an identity potentiating that is made and rearranged in the university
\end{abstract}

Keywords: High education. Kaingang. Agency. Paraná.

\section{Processos educacionais entre os Kaingang DA BACIA DO RIO TIBAgI}

O rande parte da literatura histórico-antropológica produzida sobre os Taingang - particularmente os que residem em Terras no Paraná - faz menção à presença da política como um significativo pilar da organização social desse grande grupo étnico (FERNANDES, 2003; MOTA, 1994; TOMMASINO, 1995). 0 fazer político entre os kaingang é compreendido em comparação ao que, em sua mitologia, aparece como a potência de guerra e força através da figura do jaguar $($ mig $=$ onça $)$, grande referência mítica para a constituição do ethos guerreiro kaingang, já que essa figura apresenta-se como detentor de significativa força e destreza² (RAMOS, 2006).

Os processos históricos atuam sobre a relação de apropriação das potências do jaguar que, certamente, tem sua expressão alterada. Os tempos históricos são

\footnotetext{
${ }^{2}$ A figura do jaguar representa na mitologia Kaingang a coragem, a força, ao contrário de outros animais que representariam a fraqueza. A carne do jaguar era consumida crua pelos Kaingang para que adquirissem as mesmas características do animal, ou mesmo pela simbologia em comer a carne crua, sendo esse um meio de estar mais próximo do jaguar (RAMOS, 2006).
} 
descritos por Tommasino (1995) como o Vasy ou Waxi - tempo dos antigos - e o Uri - tempo atual que despontou a partir das relações com os fóg (não índios). Se a princípio, no Vasy, a comensalidade envolvia a fabricação de corpos valentes e guerreiros, o Uri vem marcar outro momento de constituição do ethos guerreiro kaingang que, não mais pela substância direta do jaguar, mas pelas suas características de destreza e força seriam a continuidade da humanidade kaingang.

$\mathrm{Na}$ literatura sobre o grupo, a belicosidade é expressa em muitas situações do cotidiano kaingang, desde o canjire - uma prática que tinha como objetivo formar bons guerreiros através de uma luta de paus, considerada pelos colonizadores de extrema violência (RAMOS, 2006; TOMMASINO, 1995) - até as suas relações políticas com outros grupos étnicos ou mesmo com os não índios com quem tinham que se relacionar (CIMBALUK, 2013; FERNANDES, 2003; RAMOS, 2006). Sem adentrar aqui nessa vasta literatura, me reportarei aos kaingang da região Sul, mais precisamente àqueles que se localizam na Bacia do Rio Tibagi, no norte do Paraná.

Dialogando com as teorias de belicosidade e política, trato de um tema que há pouco mais de dez anos tem tomado maior dimensão entre inúmeros povos indígenas, não só os kaingang: formação superior. Desde 2002 os povos indígenas que residem no Paraná vivem a experiência de formação em cursos universitários regulares, através de vagas suplementares com a Lei $13.134^{3}$ que ampliou a atuação profissional dos Kaingang, alcançando atualmente a gestão das escolas e de seus próprios projetos nas aldeias. Foi este o tema ao qual dediquei minha pesquisa de mestrado em Antropologia Social, realizada na Universidade Federal do Paraná, entre os anos de 2012 e 2014.

Nas universidades estaduais do Paraná, uma iniciativa de grande referência foi constituir e oficializar uma Comissão em cada universidade que fizesse 0 acompanhamento dos acadêmicos, tanto em seu sentido pedagógico quanto na orientação em relação aos encaminhamentos mais burocráticos. Criou-se então em 2004 a Comissão Universidade para os Índios (CUIA), com representação local (em cada instituição) e estadual. A Comissão local é formada por docentes e dois representantes de acadêmicos indígenas. Em seu nível estadual, pelo menos três docentes representantes de cada universidade frequentam as reuniões mensais.

\footnotetext{
${ }^{3} \mathrm{Na}$ Universidade Federal do Paraná (UFPR), em Curitiba, o primeiro vestibular indígena foi realizado em 2005, mas é a instituição menos procurada pelos Kaingang e Guarani em virtude do fato de que nele podem concorrer indígenas de todo o país, enquanto nas universidades estaduais concorrem apenas os índios que têm residência há mais de dois anos no Paraná.
} 
Essa mesma Comissão é responsável pela organização, divulgação e inscrição do Vestibular. Contudo, para que o candidato tenha sua inscrição homologada é preciso que, no ato da inscrição, o cacique da Terra Indígena (T.I.), assine a declaração de pertencimento do candidato que se declarou residente em tal T.I., documento que é anexado à ficha de inscrição (RODRIGUES; WAWZYNIAK, 2006).

É nesse contexto que tomo como referência as experiências de alunos kaingang na Universidade Estadual de Londrina (UEL), onde desde 2002 até início de 2013 ingressaram 72 alunos que após sua matrícula trilharam diferentes percursos. Destaca-se que dos 72 alunos, seis concluíram a graduação ${ }^{4}$. A presença de alunos kaingang e guarani na universidade indica particularidades étnicas que devem ser consideradas, evitando o deslize da redução dessas diferenças à categoria simplificada de "alunos indígenas". Desse modo, apresento situações que perpassam o cotidiano acadêmico de alunos kaingang e guarani, porém, debruçando-me na reflexão sobre as relações entre instituição, cacique, lideranças e estudantes kaingang de duas terras indígenas: Apucaraninha, próxima ao município de Londrina, e São Jerônimo, no município de São Jerônimo da Serra.

A Terra Indígena de São Jerônimo está situada a cinco quilômetros do município de São Jerônimo da Serra. Localizada às margens do rio Tigre, afluente do rio Tibagi, sua área é de 1.330 hectares, com uma população atual de aproximadamente 674 pessoas das etnias Kaingang, Guarani Ñandeva, Xetá e não-índios, com preponderância dos kaingang. Como sua composição populacional não contempla apenas uma etnia, a representatividade política centra-se nas figuras de dois caciques, um kaingang e um guarani.

No que se refere ao trabalho remunerado, grande parte se dedica à roça em fazendas próximas e trabalhos eventuais que procuram nas cidades da região, realizando atividades que exigem pouca qualificação: serventes de pedreiro, faxineira, babá, etc. Dentro da própria terra indígena, há a possibilidade de atuarem como agentes de saúde e alguns - em sua maioria os que já frequentam o ensino superior - atuam na escola como professores bilíngues ou através do Processo Seletivo Simplificado - PSS.

\footnotetext{
${ }^{4}$ No final de 2013 mais uma aluna guarani conquistou o diploma de graduada, dessa vez no curso de Secretariado Executivo.

5 Trata-se de um processo de seleção que acontece através da apresentação de documentação comprobatória de formação superior. Essa é uma seleção realizada pela Secretaria de Educação do Estado do Paraná (SEED) para compor o quadro de professores em casos de substituição ou de falta de professores concursados que não dão conta das vagas ofertadas.
} 
Próximo à cidade de Londrina, entre os limites do município de Tamarana e o Distrito de Lerrovile, fica a T.I. Apucaraninha habitada majoritariamente pelos kaingang, porém, encontram-se lá famílias Fulni-ô e Xokleng. Esta T.I. fica a cerca de 25 quilômetros da cidade mais próxima que é Tamarana, chegando a 80 quilômetros de distância da cidade de Londrina. Tem uma área que abrange em torno de 5,5 mil hectares com aproximadamente 1.500 pessoas e está dividida em quatro áreas: Sede, Barreiro, Serrinha e Água Branca, cada qual com seu representante (CIMBALUK, 2013).

Além dos benefícios sociais e do trabalho agrícola, algumas pessoas atuam nas escolas como professores bilíngues. $\mathrm{Na}$ escola de anos iniciais todos os professores e funcionários são kaingang, com exceção da pedagoga não-índia, mas que reside há muitos anos na T.I. e dois professores de Educação Física. Há também um grande número de mulheres que confeccionam cestos, colares $\mathrm{e}$ brincos que levam para a cidade de Londrina, onde passam alguns dias para realizar a venda de seus materiais. Segundo Cimbaluk (2013), os kaingang desta T.I. foram indenizados recentemente pela Companhia Paranaense de Energia (COPEL), que responde pela construção de uma hidrelétrica que data de 1946 e com projetos que foram iniciados em 2013, como compensação pela construção da Usina Hidrelétrica de Mauá, no rio Tibagi e inaugurada em 2012.

Para o deslocamento até Londrina, os acadêmicos que vivem na T.I. São Jerônimo utilizavam uma van que saia do município de São Jerônimo da Serra. No início de 2014, após negociações junto à prefeitura, os estudantes conseguiram gratuitamente um ônibus para os seus deslocamentos até a universidade. Já no caso dos kaingang da T.I. Apucaraninha, o transporte representa um grande entrave para seu deslocamento, pois utilizam transporte particular e é recorrente a danificação dos veículos ou pequenos acidentes nas estradas.

Os kaingang mostram em seus percursos acadêmicos uma instabilidade maior que os Guarani, ocasionada por trancamento, desistências e transferências. É comum ingressarem, permanecerem alguns meses e retornarem para a aldeia, embora, voltem um tempo depois para a universidade fazendo novas tentativas de ingresso. Desse modo, conflitos e enfrentamentos são os grandes referenciais de sua permanência no ensino superior.

Relaciono esse cenário de formação acadêmica que se apresenta para os kaingang ao Uri que, conforme as análises feitas por Tommasino (1995), trata-se do tempo atual e que por sua vez, é aquele criado a partir do contato com os fóg (não índios). É, então, nesse tempo atual do Uri que se refaz o ethos guerreiro kaingang diante dos novos enfrentamentos no ambiente universitário. 


\section{TENSIONAR E NEgOCIAR: UMA REATIVAÇÃO DO ETHOS KAINGANG NO ENSINO SUPERIOR}

0 que pretendo explorar de forma breve, a partir da exposição feita acima e de outras situações que mencionarei, é a articulação entre agentes e categorias em momentos de conflito, que não se limitam às situações formais de reunião entre CUIA, estudantes e caciques. Em outras palavras, há elementos comuns que permeiam as relações dos diferentes agentes, como é o caso da reciprocidade e da noção de dívida e dádiva.

Acessar o espaço da universidade se tornou uma nova oportunidade de viver experiências que não apenas se referem a ter um curso superior, mas também envolvem desejos e curiosidades de desfrutar outros ambientes, sensações, conhecimentos e se distanciar do controle sobre as ações vivenciadas nas aldeias (PALADINO, 2006).

0 fato de estar na universidade provoca também uma reelaboração das formas de construção de si, de seu corpo e de seu comportamento, o que não se refere a uma diluição étnica, mas sim o contrário disso, pois: "a lógica interétnica não equivale à submissão à lógica externa nem à lógica do mais forte. É antes um modo de organizar as relações com estas outras lógicas" (CUNHA, 2009, p. 356).

Aqui, cabe pensar na percepção de agência no sentido que é colocado por Sherry Ortner (2007), em que a intencionalidade toma o espaço central de debate. 0 que a autora propõe, em diálogo com a teoria da prática, é que se faça uma análise tanto das desigualdades de poder, quanto das estratégias criadas para caminhar dentro dessas situações.

0 conceito de agência para Ortner passa por duas concepções que se completam, sendo elas a "agência de poder", situada no campo da desigualdade; mas também a "agência de projetos", que se refere às intencionalidades e projetos dos sujeitos. A agência de projetos pode ser encarada como resistência a uma possível situação de dominação, mas diz respeito também a "pessoas que nutrem desejos de ir além de suas próprias estruturas de desigualdade." (ORTNER, 2007, p. 68). Dessa forma, o ponto central para se pensar na agência é tanto a importância dos projetos, quanto o que Ortner chamou de "instabilidade do poder", isto é, nenhuma situação de dominação deve ser vista como acima do poder de (re) ação dos sujeitos.

Desse modo, essa política afirmativa apresenta dois significativos efeitos políticos, que não são excludentes: um efeito que se relaciona intimamente com 
os projetos voltados às T.I.s, chamados de projetos coletivos, seja inseridos nas aldeias ou por meio da ocupação de cargos de poder em órgãos que atendam aos anseios indígenas, bem como o efeito gerado a partir da ocupação de espaços cujos atendimentos são voltados para uma população majoritariamente não indígena.

É o primeiro aspecto que toma maior espaço nos discursos de alunos, caciques e professores não indígenas, ainda que em algumas situações esses alunos problematizem o retorno como um fato não garantido, dependendo de decisões políticas internas de cada T.I., assim como da relação mantida com 0 cacique e as lideranças. É nesse caso em que a reciprocidade obrigatória, nos mesmos termos de Mauss (1974) pode ser compreendida, sobretudo quando pensada a partir do poder exercido pelos caciques.

A autoridade do cacique está presente em sua assinatura na ficha de inscrição que sugere aos futuros acadêmicos as responsabilidades que devem assumir com a T.I. após o ingresso na universidade. Em algumas visitas que fiz às aldeias com a equipe da CUIA para a divulgação e inscrição do Vestibular, presenciei a performance discursiva de caciques kaingang que enfatizavam aos futuros candidatos o peso político contido em sua assinatura, destacando nisso a obrigação do retorno para T.I. após a conclusão do curso.

Firma-se a partir desse momento - em que a fala dura do cacique já indica o caminho que deve ser trilhado pelos candidatos - uma relação de obrigação, tomando a forma de um contrato. Entretanto, essa relação não se restringe ao compromisso que deve ter 0 acadêmico, mas diz respeito também ao próprio cacique que deve o "apoiá-lo" além da retórica. Essa obrigação alcança, ainda, a universidade, já que receberá os kaingang e precisa de mecanismos que os acolha em suas particularidades étnico-educativas. Considero esse acordo inicial entre as partes envolvidas como o evento principal de constituição dos sentidos de reciprocidade e também de dívida na formação superior indígena.

Entre meus interlocutores kaingang há o discurso da coletividade de projetos e, portanto, o compromisso em cumprir o acordo inicial firmado formar-se e retornar para a T.I. - que revela uma moralidade presente no ato de retribuir um bem que lhes foi concedido pelo cacique e pela comunidade, o que fica expresso na resposta de Ângelo, quando lhe pergunto sobre a necessidade de retornar ou não para a T.I.: 
Acho ruim falar disso aí. É complicada essa situação, porque se 0 cacique depositou uma confiança é porque ele precisa de alguém pra auxiliar ele na reserva, que tem estudo no ensino superior e a pessoa saiu da comunidade com 0 aval do cacique e não voltar eu acho uma sacanagem da parte de quem não volta. Querendo ou não, quanto mais gente lá pra dialogar e resolver problemas dentro da nossa comunidade acho muito melhor, todo mundo que tem ensino superior indígena voltar pra dentro da nossa casa né, porque querendo ou não a reserva indígena é nossa casa, acho que todo cara, tanto índio como branco que sai da casa tem desejo de voltar pra casa dele, pra mostrar pra família que conseguiu, e a família nossa é a comunidade (Ângelo, acadêmico kaingang no curso de Educação Física).

Essa preocupação de Ângelo se articula com a reflexão feita por Marcel Mauss ao olhar para os processos de troca, dádiva e reciprocidade entre os Maori. Nesses movimentos, Mauss identificou aquilo que seria o sentido dessas relações de dar, receber e retribuir: o hau. Trata-se do "espírito da coisa dada" (MAUSS, 1974, p. 52).

A potência do hau exercendo influência na tomada de decisões para que se retribua 0 bem dado, representa um dinamismo nas relações que tem a reciprocidade da troca como referência de uma sociabilidade que é preciso respeitar e dar continuidade: "esta coisa dada não é coisa inerte. Animada, amiúde e individualizada, tende a regressar àquilo que Hertz chamava de seu lar de origem ou a produzir, para o clã de onde saiu, um equivalente que a substitua." (MAUSS, 1974, p. 56).

Desse modo é possível articular o momento em que se estabelece 0 vínculo de compromisso/obrigação - que antecede ao ingresso - às obrigações de troca e, sobretudo de dádiva para que as boas relações entre os kaingang sejam garantidas. A confiança concedida pelo cacique, como mencionou Ângelo, oportuniza as novas experiências tão procuradas pelos kaingang, mas ao mesmo tempo lhes cobra 0 retorno. Há aí a necessidade da circulação dos bens não materiais (demonstrações de compromisso e respeito) para que a aliança seja fortalecida.

Como argumenta Mauss (1974, p. 54-55):

0 que, no presente retribuído e trocado, cria uma obrigação, é o fato de que a coisa recebida não é inerte. Mesmo abandonada pelo doador, ela ainda é algo dele. Por meio dela, o doador tem uma ascendência 
sobre 0 beneficiário, assim como o proprietário tem, por meio da coisa, uma ascendência sobre o ladrão [...] o hau persegue o detentor. [...] No fundo é o hau que quer regressar ao local do nascimento.

Como disse anteriormente, todos os alunos kaingang (com exceção de uma aluna) residem e trabalham na T.I., deslocando-se diariamente para a cidade de Londrina. Esses deslocamentos limitam a participação dos kaingang em algumas atividades propostas pela CUIA ou pelos colegiados, já que chegam na universidade no horário da aula e por trabalharem o dia todo, as atividades em contra-turno na universidade são, na maioria das vezes, descartadas por eles.

Esse tem sido um tema presente em diversas reuniões da CUIA, aventando possibilidades de articulação entre esses dois espaços, sem prejuízo para algum deles. Entretanto, os kaingang são enfáticos ao afirmarem que o trabalho na aldeia possui uma forte centralidade em suas vidas, deixando as atividades acadêmicas para um segundo plano e, se necessário, afastando-se da universidade para que não tenham seus trabalhos colocados em risco.

Mariana, aluna de Pedagogia e moradora da terra indígena Apucaraninha, ocupa o cargo de diretora na escola de anos iniciais João Kavagtan, mesmo sem ocupar o Quadro Próprio do Magistério, pois ainda não concluiu nenhum curso superior. Esse cargo é percebido por ela e pelos demais kaingang como uma grande conquista junto ao Ministério Público Federal, pois enfatizam que isso só foi possível após o enfrentamento de lideranças e cacique que exigiram a representação kaingang na diretoria da escola, indicando o nome de Mariana:

No início até falei pra minha mãe: 'eu vou largar do meu trabalho, acho que só vou estudar'. Aí ela disse assim: 'você pensa bem, porque você tem seus filhos, como você vai criar?' Aí já fica meio assim, daí a própria liderança falou assim pra mim 'se você for estudar quem vai ficar na escola, você sabe que você ajuda muito na escola, se você sair como que vai ficar nessa escola?

Se, por um lado a maioria dos kaingang faz o deslocamento diário e mantem seu compromisso com a T.I. através de seu trabalho, há aqueles que se mudam para a cidade e buscam outros meios para não quebrar a confiança de lideranças e parentes. Marcela, kaingang da T.I. São Jerônimo, mudou-se para Londrina e tem nas viagens de eventos políticos um meio de manter seu elo com 
os grupos de sua aldeia. Para Ramos, a viagem é compreendida entre os kaingang como um fator de grande relevância para demonstrar os interesses e compromissos:

[...] para as lideranças Kaingang, as viagens são vistas como muito importantes, mais do que propriamente os resultados que delas podem auferir. Além do gosto mesmo que os Kaingang têm pela viagem [...] para os lideres ela e uma forma de demonstrar para a sua comunidade que são boas lideranças, que trabalham muito, que lutam pela comunidade (RAMOS, 2006, p. 67).

Desse modo, há um sentido moral em honrar o compromisso que, por sua vez, é relembrado pelo cacique. Cimbaluk (2013), ao se referir à organização política kaingang também na T.I. Apucaraninha, ressalta a moralidade que envolve a figura do cacique, entendendo-a como essencial para a legitimidade e permanência nessa posição por ser um representante político, "conciliador", "aconselhador", não podendo então "errar". Essa mesma relação de moralidade e 0 risco do "erro" pode ser transposta para os acadêmicos que passam a ocupar também um lugar de destaque na T.I. e fora dela.

Nas observações de Cimbaluk (2013):

Outro plano da moralidade está mais diretamente ligado à sociabilidade e à reciprocidade. Ele pode ser positivo, seja através do trabalho ou da generosidade, reforçando as parentagens e vínculos entre algumas delas, mas pode ser negativo, no sentido de ações que tendem a enfraquecer tais vínculos, como a negação do compadrio ou pessoas que se vêem prejudicadas ou menos beneficiadas na esfera da generosidade devida pelo chefe. A moralidade pode levar à prisão, pode demarcar status (sempre temporários e relacionais), pode aproximar ou afastar (CIMBALUK, 2013, p. 124).

Assim, caso a confiança que se estabelece por meio da reciprocidade (compromisso moral em honrar as atividades de trabalho dentro da T.I.) seja quebrada, os espaços de atuação vão fechando-se e, ainda, esses kaingang podem ser comparados aos fóg, destacando o distanciamento das atividades $\mathrm{da} / \mathrm{na}$ aldeia como um processo de virar branco. 
Ainda em termos de moralidade e reciprocidade há outro elemento de grande referência que surge nessas interações, que é a noção de "dívida", relacionada aos parentes e lideranças, ao Estado e também à rede de relações que construíram com professores e acadêmicos não indígenas durante as tentativas de continuidade no ensino superior. Para Roberto, a dívida em questão caminha em sentido não apenas de retribuição à sua Terra Indígena, mas também ao Estado:

Quase desisti mês passado. Aí eu pensei: 'o Estado tá dando bolsa, não é bastante, mas dá pra transporte, comida, dá pra sobreviver'. Às vezes saí até lágrima do olho quando penso nisso. Eu queria terminar, só que a situação que a gente se encontra não dá. Se eu parar de novo vou sentir como uma coisa roubada dali, o Estado deu esse dinheiro pra mim estudar, continuar e eu não vou dar retorno? (Roberto, acadêmico kaingang no curso de Artes Visuais, residente na T.I. Apucaraninha).

Embora Roberto tenha se referido ao Estado, a ênfase que se dá à dívida não tem o Estado e universidade como agentes centrais a quem se deve. Estes tomam, ao contrário, uma característica predominante de devedores. A interação dos kaingang com os agentes institucionais dá à dívida um sentido oscilante, ora compreendendo-a como um "erro" próprio, em que a moralidade kaingang entra em questão, ora como um "erro" institucional, colocando em xeque a moralidade de outros agentes.

Algumas dessas discussões são geradas pela cobrança da CUIA em relação à participação indígena em reuniões e monitorias, mas também pela cobrança de alunos à CUIA para que refaçam o método de diálogo e encontro com os alunos, outro método além das reuniões que, conforme me disse um kaingang, seriam sempre iguais e com a cobrança como elemento norteador. Há então nessa relação de oposição e complementaridade uma noção de dívida (pois há a cobrança) mútua, que evidencia os limites (de cumprir compromissos firmados) dos próprios alunos e da instituição.

Na pesquisa feita por Tommasino em meados da década de noventa entre os kaingang da Bacia do Rio Tibagi, identifica-se nas relações entre índios e fóg, 0 seguinte:

Tanto os funcionários indigenistas quanto as autoridades municipais são unânimes em afirmar que os índios são muito 'pidões', esperando 
que 0 Estado lhes dê generosamente tudo que desejam, de alimentos e roupas a transporte e construções de escolas [...] Os índios interpretam experiências passadas e presentes da relação indigenismo/indígenas como relação de escravidão. Os índios que ocuparam funções de capitão e de cacique são unânimes em afirmar que trabalharam como auxiliares da administração dos postos, com funções definidas e documentos de nomeação assinados pelos superiores sem ter qualquer remuneração (TOMMASINO, 1995, p. 287).

Atualmente, caciques e lideranças kaingang reafirmam seu papel de "voluntário", já que não recebem por essa função e que, portanto, não estão disponíveis para os fóg a todo e qualquer momento. Não se limitando aos caciques, é possível notar entre os kaingang um peso maior nas cobranças feitas para a universidade ao entenderem que a universidade tem uma "obrigação" a cumprir com eles, relembrando dessa situação de "escravidão" que é mencionada por Tommasino.

Essa cobrança e o reconhecimento da dívida mútua é comentada por Marcela, kaingang da T.I. São Jerônimo em uma das reuniões: "Estamos em falta com a Universidade, mas e a universidade? Nos afastamos da UEL, não entre nós". Esse afastamento é visto como resultado da ausência de ações da universidade, pois ela é que deveria propiciar 0 ambiente de diálogo para bons acordos, oferecendo algo além das vagas no ensino superior.

A relação entre dívida, moralidade e reciprocidade faz emergir, nas interações dessas categorias e dos agentes, o ethos guerreiro kaingang, revelando o prazer pelas relações bélicas que, agora no Uri - tempo atual - se refaz. 0 ethos kaingang (RAMOS, 2006) a que me refiro, não é no sentido da comensalidade a que estava relacionado a figura do Jaguar, mas se trata de concebê-lo no Uri (TOMMASINO, 1992, 1995) e identificando suas potenciais transformações, para que seja possível compreender o modo de agir kaingang dentro da universidade.

Como ressaltou Ramos (2006), os conflitos kaingang diferenciam-se em seu sentido e objetivo conforme a identificação do grupo contrário. Isto é, os conflitos entre os kaingang e outro grupo indígena não terão a mesma orientação que os conflitos travados com os fóg, que seria basicamente para "adquirir bens, para se vingar ou para defender seus territórios” (RAMOS, 2006 p. 111).

0 mesmo ocorre nas relações entre alunos kaingang e instituição. Diferente da aliança firmada dentro da terra indígena, na universidade os kaingang agem de 
forma mais dura, tanto aqueles que estão há algum tempo na universidade, quanto os novos ingressantes. Os primeiros, cansados das promessas da CUIA, como me diziam, iniciam as negociações em momentos de reunião com grande resistência e enfrentamento. As maiores discussões geradas que eu pude presenciar na UEL tiveram como protagonistas os alunos kaingang. Os alunos que acabam de ingressar tomam para si os embates que já foram travados por aqueles que os antecederam - como se o "herdassem" - e se "armam" contra os discursos institucionais, mesmo que ainda não os tenham ouvido.

Quando fazia minha pesquisa de campo em 2013, acompanhei uma roda de conversa que aconteceu como parte da Semana de Ciências Sociais da UEL. Foi necessária uma única pergunta de uma participante não indígena para que os ânimos ficassem exaltados, desencadeando então uma discussão que saiu dos limites do tema proposto pelo encontro - "Diálogos sobre estudantes indígenas no ensino superior" - gerando um clima de cobranças e desentendimentos entre alunos e CUIA.

A pergunta, já frequente, foi sobre o desejo ou não de retorno para a T.I.. Diferentes respostas foram surgindo, desde o interesse e compromisso político em retornarem, passando pelos conflitos internos que impossibilitam o retorno. Após rápidas respostas, entraram em debate assuntos pessoais e relativos às situações de anos anteriores que, para quem não fazia parte dos espaços em comum aos agentes ali envolvidos, poderiam não entender ao certo o fundamento dos desacordos, como eu mesma que, embora já familiarizada com essas relações, não compreendi.

Passado o momento de minha própria confusão diante do novo cenário que se formava, foi possível compreender os locais e sentidos de fala dos alunos presentes. Sem surpresa, os alunos que mais se manifestavam durante o encontro eram meus interlocutores, o que dá um maior respaldo para as relações que aqui proponho.

Enquanto, novamente, os kaingang questionavam veementes em seu estilo firme e em tom sarcástico, utilizando a memória para retornarem ao passado que tiveram na universidade, reafirmando a dívida desta com os estudantes, os guarani, com o mesmo recurso da memória, interpelavam a discussão tateando algum consenso, como se ocupassem ali um papel de mediadores do conflito. Esse mesmo posicionamento é recorrente em outras situações dentro da universidade. Os guarani igualmente cobram, mas de um modo que entendo como "diplomático", dialogando e manejando as regras do jogo, mas sem serem 
dominados por elas. Os kaingang, por outro lado, buscam refazer as regras do jogo através do embate.

Havia nessa reunião alguns alunos que já conheciam mais de perto a estrutura acadêmica, dentre eles estavam meus interlocutores kaingang. 0 posicionamento dos mais novos na universidade, diante de qualquer proposta da CUIA era aproximado ao dos que estavam há algum tempo na UEL. Com reações exaltadas e firmes os kaingang em suas falas, gestos e olhares de reprovação, faziam confundir o insulto e a ironia, o que parecia desconcertar os quatro integrantes da CUIA presentes na reunião.

Uma árdua disputa pela palavra foi travada durante toda tarde de reunião, buscando reduzir o espaço de fala institucional, causando mais descontentamento dos docentes. Pierre Clastres menciona o poder da palavra dos chefes entre os povos sem Estado, como sendo um "dever do poder", em que se espera que 0 chefe tenha uma boa retórica, pois "chefe silencioso não é mais um chefe" (CLASTRES, 2012, p. 170). Dessa maneira, sendo a palavra uma expressão de poder e, não havendo entre os estudantes indígenas um chefe, esse poder foi distribuído entre eles. Buscava-se a todo tempo pelos espaços de fala, através de uma encenação com o que (quem) representa perigo, pois representa poder; uma encenação com estilos diferentes - visto as diferenças de interação dos kaingang e guarani - com fins de se estabelecerem como sujeitos ativos da situação, através da ironia, do domínio da palavra e da desestabilização de seus interlocutores.

Entre as tentativas de se chegar ao consenso durante a reunião, era possível notar que a revolta era também tomada, em alguns momentos, pela jocosidade expressa por meio do riso, cochichos e troca de olhares, sem, contudo, perder a seriedade da discussão.

Rir nesses momentos de negociação política na universidade não indica 0 desrespeito aos não indígenas ali presente com quem tentam dialogar, afinal também os reconhece como aliados. Não há nessas ações uma tentativa de anular a relevância desses encontros ou mesmo de ridicularizar a situação e quem dela participava. Isso ficou evidente quando os próprios kaingang me diziam que compreendem a situação dos docentes da CUIA, sobretudo daqueles que mais participam ativamente da Comissão, mas que era preciso criar discussão para que não houvesse uma acomodação por parte da CUIA.

0 interesse pelo riso nas abordagens antropológicas revela dimensões das relações sociais, ressaltando características de extrema importância que dialogam com minhas observações em campo. Antes dessas associações, é importante colocar em evidência a seguinte consideração feita por Els Lagrou: 
0 pensamento acadêmico dá prova de uma histórica falta de senso de humor e demonstra uma dificuldade de pensar o riso e o risível como temas relevantes em análises 'sérias' de sistemas sociais, políticos ou cosmológicos. Seria a antropologia, além de constitutivamente uma antiarte (Gell, 1992), também essencialmente anti-humorística? 0 riso e a arte aparecem nesse paradoxo como tópicos relacionados, tanto no que se refere ao fascínio que exerceram sobre 0 pensamento e a filosofia modernos quanto no que se refere à dificuldade de escrever algo antropologicamente 'novo' ou 'certo' sobre eles (LAGROU, 2006, p. 57).

Considero pertinente essa análise sobre o lugar do riso nas pesquisas acadêmicas para que se compreenda que, ao tomar o riso como um dado etnográfico, não há a intenção em depreciar quaisquer relações, sujeitos ou posturas. Mas, ao contrário disso, me proponho a tomá-lo como uma expressão que indica novos olhares para as interações de kaingang e guarani com seus outros não-indígenas, sobretudo quando esses outros ocupam espaços de poder, como é o caso dos docentes que integram a CUIA e são, além disso, agentes institucionais.

0 Riso, 0 ar jocoso desses momentos parecia indicar uma provocação necessária para conhecer os limites do outro, uma estratégia kaingang para tentar dominar as regras do jogo, bem como um meio de produzir conflito para que conseguissem falar a mesma língua. Dessa maneira, o riso, além de sua tradução primeira - a alegria - tem sua significação ampliada, podendo ser interpretado como controle social (LAGROU, 2006, p. 59). Essa noção de controle social contempla 0 sentido do riso que apresento, pois o desejo ali era desestabilizar aquele que tem poder para então dar início às negociações.

Ao final de toda a agitação os professores da CUIA propuseram um meio de os alunos kaingang (pois são os que residem na aldeia) irem para a universidade no período diurno para que pudessem aproveitar algumas atividades extracurriculares. Nessa reunião negociava-se com algumas alunas que acabavam de ingressar na universidade. A proposta feita pela CUIA foi de que os kaingang fossem uma vez por semana - depois reduzido para uma vez ao mês - à UEL para realizarem atividades extracurriculares e monitorias, com o objetivo de uma maior utilização do espaço universitário. A reação primeira das alunas foi de recusa e agitação, pois trabalhavam e não poderiam se ausentar nenhum dia.

Mesmo com as recusas, foi negociada a formação de um grupo com representantes de cada T.I. para que se reunissem e definissem pautas para os próximos encontros e oficinas. Na semana seguinte, as fortes chuvas impediram a 
presença kaingang no grupo, que também não teve mais continuidade. Assim, o riso tem seu sentido transformado, após terem sido atingidos os objetivos primeiros. Ou seja, "trata-se de um riso provocador, libertador e divino, como queria Nietzsche, para se tornar depois um riso cada vez mais melancólico: um riso humanista e niilista, um riso banal e sutil." (LAGROU, 2006, p. 72).

Toda a reação dos professores da CUIA, sobretudo de dois dos quatro presentes, oscilava da sobriedade à impaciência, trocando com os kaingang 0 tom de ironia e sarcasmo, demonstrando em alguns momentos uma tensão em suas posturas que se aproximava de um cansaço, dado que toda a pressão presente nos discursos recaía sobre eles, representantes institucionais que mantém maior proximidade dos alunos. Dado os efeitos da estratégia kaingang, partilho da seguinte afirmativa: "o poder provoca 0 riso assim como 0 próprio riso tem poder.” (LAGROU, 2006, p. 56).

\section{CONSIDERAÇÕES FINAIS}

As cobranças e a negociação das dívidas entre os agentes mencionados geram uma reciprocidade negativa, ou seja, surgem as discordâncias, conflitos e guerras, compreendidos no Uri como o embate político dentro da universidade, dando continuidade ao conflito histórico com os fóg. Por outro lado, é preciso compreender que esse ethos guerreiro no Uri é relacional, envolve agentes não indígenas que não apenas são, em algum momento, "adversários", mas são, em outros momentos, aliados.

É preciso considerar também que as ações não se esgotam em reciprocidade positiva ou negativa, mas há, ao contrário disso, um vai e vem dos sentidos contidos na reciprocidade que envolve os kaingang, visto que é grande a possibilidade de desacordos e conflitos gerarem uma situação de reciprocidade positiva e entendimentos, mas que, por sua vez, é sempre colocada em risco pelo modo kaingang de fazer negociações.

Dessa maneira, ainda que seja presente essa reciprocidade negativa, ela aparece entre os kaingang como algo necessário, pois mesmo sendo negativa, ela é, na verdade, carregada de atributos que são positivos para a continuidade de um ethos combativo. 


\section{REFERÊNCIAS}

CUNHA, Manuela Carneiro da. "Cultura" e cultura: conhecimentos tradicionais e direitos intelectuais. In: . Cultura com aspas: e outros ensaios. São Paulo: Cosac Naify, 2009.

CIMBALUK, Lucas. A criação da aldeia Água Branca na Terra Indígena Kaingang Apucaraninha: "política interna", moralidade e cultura. 2013. 250 fls. Dissertação (Mestrado em Antropologia Social) - Universidade Federal do Paraná, Curitiba, 2013.

CLASTRES, Pierre. Sociedade contra o Estado: pesquisas de antropologia política. São Paulo: Cosac Naify, 2012.

FERNANDES, R. C. Política e parentesco entre os Kaingang: uma análise etnológica. 2003. 288 fls. Tese (Doutorado em Antropologia Social) Universidade de São Paulo, São Paulo, 2003.

LAGROU, Els. Rir do poder e o poder do riso nas narrativas e performances Kaxinawá. Revista de Antropologia, São Paulo, v. 49, n. 1, p. 55-90, 2006.

MAUSS, Marcel. Ensaio sobre a dádiva: forma e razão da troca nas sociedades arcaicas. In: . Sociologia e antropologia. São Paulo: EPU: EDUSP, 1974. v. 2.

MOTA, Lucio Tadeu. As guerras dos índios Kaingang: a história épica dos índios Kaingang no Paraná (1769-1924). Maringá: EDUEM, 1994.

ORTNER, Sherry B. Poder e projetos: reflexões sobre a agência. In: GROSSI, Mirian Pillar; ECKERT, Cornelia; FRY, Peter Henry (Org.). Conferências e diálogos: saberes e práticas antropológicas. Blumenau: Nova Letra, 2007.

PALADINO, Mariana. Estudar e Experimentar a cidade: Trajetórias sociais, escolarização e experiência urbana entre "Jovens"indigenas ticuna, Amazonas. 2006. 352 fls. Tese (Doutorado em Antropologia Social) - Universidade Federal do Rio de Janeiro, Rio de Janeiro, 2006.

RAMOS, Luciana Maria de Moura. Venh Jykre e Ke Ha Han Ke: Permanência e Mudança do Sistema Jurídico dos Kaingang no Tibagi. 2008. 252 fls. Tese (Doutorado em Antropologia Social) - Universidade de Brasília, Brasília, 2008.

RODRIGUES, Isabel Cristina; WAWZYNIAK, João Valentin. Inclusão e permanência de estudantes indígenas no ensino superior público no Paraná: reflexões. 2006. Disponível em: <www.acoesafirmativas.ufscar.br/relatorioCUIA.pdf > . Acesso em: 08 jun. 2009. 
TOMMASINO, Kimiye. A bistória dos Kaingang da bacia do Tibagi: uma sociedade Jê meridional em movimento. 1995. 348 fls. Tese (Doutorado em Antropologia Social) - Universidade de São Paulo, São Paulo, 1995.

TOMMASINO, Kimiye. Os Kaingang e os Guarani no Paraná: inimigos míticos no passado, aliados políticos no presente. In: Reunião da Associação Brasileira de Antropologia - ABA, 18., 1992. Belo Horizonte, 1992. 